\title{
Comparison of Manipulation-proof Measures on Hungarian Data*
}

\author{
Dávid Andor Rácz
}

The further development of performance measures has managed to remedy some of the problems with earlier solutions, but with regard to the measures used most widely today, the issue of performance manipulation still needs to be tackled. This article presents the manipulation-proof performance measure (MPPM) developed by Ingersoll et al. (2007), which addresses this problem in a general sense. The MPPM used by Brown et al. (2010) is also detailed, along with the doubt ratio they developed, which can be used as a manipulation-detecting measure assessing implied risk aversion. With the calculations included here, this paper is one of the first to compare the MPPM and doubt ratio values calculated with the methods of the two groups of authors, seeking to explain the differences by using data from Hungarian absolute return funds as a sample. The results allow the author to be the first to propose the use of the more accurate MPPM formula of Ingersoll et al. (2007) both for performance measurement and calculation of the doubt ratio.

Journal of Economic Literature (JEL) codes: G11, G23

Keywords: portfolio selection, investment decisions, investment funds, performance assessment

\section{Introduction}

Although traditional performance measures have eliminated the faults of earlier solutions in the course of their development, potential manipulation is still an issue in connection with the measures widely cited in the literature and currently used by the market. One possible solution to this problem is to use manipulation-proof performance measures (hereinafter: MPPM), based on the utility theory well known in microeconomics. Due to their structure, these measures are especially suited for assessing actively managed funds, since their value can only be increased if

\footnotetext{
* The papers in this issue contain the views of the authors which are not necessarily the same as the official views of the Magyar Nemzeti Bank.

Dávid Andor Rácz is a PhD Candidate at the Business and Management PhD Programme of the Corvinus University of Budapest. E-mail: raczdavidandor@gmail.com

I am indebted to Péter Csóka and Miklós Pintér for their valuable remarks and ideas. I am also grateful to the two anonymous reviewers for their constructive comments and suggestions.

The Hungarian manuscript was received on 19 November 2018.
}

DOI: http://doi.org/10.33893/FER.18.2.3151 
the fund manager has actual information or skills. By contrast, it is impossible to enhance a fund's score just by knowing the measure used by the market or the performance assessor for performance measurement. This special feature sets apart manipulation-proof performance measures from traditional indicators, which can be manipulated without extra knowledge or information, simply by knowing the indicator.

The article presents the requirements that manipulation-proof measures need to meet and how Ingersoll et al. (2007) produced a possible solution to the problem and describes the measure defined by Ingersoll et al. (hereinafter: Ingersoll measure). The study also touches on the approach used by Brown et al. (2010) (hereinafter: Brown approach), which is a linear approximation of the Ingersoll formula. The Brown approach allows the measure to be better structured with excess return and excess standard deviation, and therefore it can also be used to assess implied risk aversion. The new indicator derived in this manner is referred to as the doubt ratio, which can indicate the presence of return smoothing or performance manipulation in the case of extreme values. As Brown et al. (2010) offered several ways to calculate the doubt ratio, including calculation of the MPPM with various risk aversion factors, not only the Ingersoll and Brown MPPM values were calculated here, but also the doubt ratios based on them.

The article looks at issues previously not discussed: What is the relationship between the results of the Ingersoll and the Brown MPPM and the doubt ratio (implied risk aversion)? What could explain any differences detected? Taking into account the results and the practical calculation requirements of the two different methods, which method should be used for calculating the MPPM and the doubt ratio? Using data from Hungarian absolute return investment funds as a sample, our own calculations are used to show that the results of the Ingersoll and the Brown MPPM and doubt ratio almost completely overlap; however, the difference between them and the corresponding reasons are also indicated.

The study is structured as follows: Section 2 describes the characteristics of manipulation-proof performance measures, providing Ingersoll's solution. Section 3 then outlines the identification of manipulated performance, the Brown approach and the doubt ratio defined by them. After that, Section 4 compares the Ingersoll and Brown MPPM values and doubt ratios using data from Hungarian absolute return investment funds, and determines which method should be used in which situation, based on the results and the complexity of the calculations in practice. The paper ends with a brief summary and the conclusions. 


\section{Manipulation-proof performance measures}

Based on the literature, the assessment of actively managed portfolios can be approached from several aspects: Amihud et al. (2015) analyse the effect of the pricing of illiquidity, Gemmill et al. (2006) assess investment funds taking into account loss aversion. When examining fair risk allocation, Csóka and Pintér (2016) acknowledge and Balog et al. (2017) clarify that there is no risk allocation method that is always applicable, stable and motivating at the same time. Zawadowski (2017) presents a disappointing correlation in investment fund managers' focus on commission, because according to his results, the fund managers who demand a higher commission cannot generate more excess return than that in exchange: on the contrary, 1 percentage point higher fees are coupled with over 1 percentage point lower performance on average (Jensen's alpha) compared to the benchmark rate. There is ample literature on measuring the returns and risks of investment funds as well as identifying the factors that influence fund performance. ${ }^{1}$

Traditional performance measures have eliminated the faults of earlier solutions during the course of their development. The Sharpe ratio (Sharpe 1966) only explains whether an investment fund provides adequate excess return for one unit of excess risk taken, but it does not show the relationship between the benchmark and the investment fund's performance, in other words it does not break down investment fund performance into the performance arising from the change in the market/benchmark and the performance arising from the individual decisions of the investment fund manager. Therefore, it cannot be used to determine how exactly the fund manager was able to underperform or outperform the benchmark.

On the other hand, Jensen's alpha (Jensen 1969) clearly demonstrates superior and inferior performance compared to the benchmark index, and its calculation is also fairly simple. The problem with it, however, is that it only shows the return achieved by the fund manager relative to the benchmark, but not the additional risk taken. The extent to which the portfolio created by the fund manager through overweighting is riskier than the benchmark cannot be ascertained.

The information ratio (Treynor and Black 1973) combines the two approaches, as it shows the excess return achieved by the fund manager for one unit of risk actively taken (Jensen's alpha divided by its standard deviation). The information ratio is basically a modified Sharpe ratio: instead of the risk-free rate, the excess return relative to the benchmark is compared to the additional risk taken relative to the benchmark index.

${ }^{1}$ Blake et al. (1993); Elton et al. (1996a); Carhart (1997); Bóta and Ormos (2016); Erdős and Ormos (2009); Bóta (2014) 
However, when assessing absolute return investment funds, the lack of an appropriate benchmark index is a huge problem, as these investment funds do not track clearly and properly defined indices. Instead, they aim to achieve positive returns in all market conditions, coupled with low volatility. The literature offers several approaches to manage this problem. These seek to introduce performance measures that are independent from benchmarks and able to appropriately assess the risk-return combinations even if the return distribution of the investment fund is abnormal. One possible solution is to use factors representing investment styles to calculate a modified information ratio (Pojarliev and Levich 2013). However, using the necessary factors is quite difficult in the case of these investment funds. Another issue is manipulation. ${ }^{2}$ The other possible solution for the problem related to the assessment of absolute return investment funds is to use manipulation-proof performance measures.

This article does not use the term "manipulation-proof" in the sense of non-manipulability from the Gibbard-Satterthwaite theorem well known in microeconomics. ${ }^{3}$ Here, the focus is not on how vulnerable a social choice function is to manipulation. Instead, what is attempted here is to prevent fund managers from boosting their own performance-based remuneration and bonuses simply by being familiar with the performance measure which is used to assess them. Fund managers who have no material extra knowledge or information to base their investment decisions on, but are aware of the weaknesses of the measure used for assessing them should not be able to make decisions that do not in fact increase the utility of the investors holding the investment fund but still raise the value of the assessment measure. The goal is to use an assessment system that rewards only those investment decisions that truly enhance the utility of investors, those that can only be made by fund managers who have more information or better skills than the market, and use these to effectively and profitably deviate from the market benchmark portfolio's composition.

It has already been demonstrated that there are trading and reporting techniques that boost the value of traditional performance measures without actually increasing the investors' utility on the risk-return spectrum. These methods can be best illustrated in the case of the Sharpe ratio, because it has a relatively simple structure: it compares the excess return over the risk-free rate to the standard deviation of the portfolio. One possible manipulation is so-called return smoothing, when fund managers report their losses stretched out and averaged out for a longer period, for example by subjectively stating assets that are illiquid, rarely priced and difficult to assess (Abdulali 2006). The reported average excess return does not change, but the detected standard deviation declines, and therefore ultimately

${ }^{2}$ Abdulali (2006); Bollen and Pool (2009); Ingersoll et al. (2007); Qian and Yu (2015)

${ }^{3}$ See, for example, Mas-Colell et al. (1995) Chapter 23 
the risk-adjusted performance appears to improve. There is also so-called dynamic manipulation when, for example, after a lucky gain at the beginning of the period under review the fund manager protects the profits by resorting to risk-free investments for the remaining period, making the risk-adjusted performance high, since its standard deviation will be close to zero. However, this choice is still suboptimal, and it does not provide the greatest utility to investors, because the fund manager should probably hold some risky assets in the remaining period, too. Ingersoll et al. (2007) present other investment strategies using options as well, which result in unreasonably high Sharpe ratio values. For example, the fund manager sells an OTM option with 1-month maturity at the beginning of the period, and the money from that as well as the already existing funds are invested in riskfree assets. If the option expires worthless (the probability of this is strictly positive), the fund manager achieves positive returns with zero standard deviation and thus an infinite Sharpe ratio. Due to the positive probability, the expected value of this strategy also generates an infinite Sharpe ratio.

Nevertheless, it was also shown that there may exist properly constructed performance measures that are able to eliminate the above-mentioned problems based on a utility approach. The results of manipulation-proof performance measures cannot be improved by smoothing in the reports, in other words returns reported averaged out, leaving the average return unchanged. Moreover, the value of manipulation-proof performance measures can only be increased by deviating from the market benchmark portfolio by overweighting certain investment elements. These investment decisions are based on fund managers' extra information compared to the market or their ability to create genuine value added, thanks to their timing and selection skills. Another advantage is that these measures' assumptions do not include the normal distribution of returns, and therefore their results are less distorted in the case of a skewed or fat-tailed distribution of returns, in contrast to traditional performance measures that typically assume normal distribution and thus are more sensitive to the distortions caused by the abnormal distributions seen in real life.

Manipulation-proof performance measures are characterised by the following conditions:

1) They should generate a single valued score for ranking.

2) The score should not depend upon the portfolio's monetary value, only the return percentage.

3) Uninformed investors should not achieve a higher estimated score by deviating from the benchmark, however, informed investors should be able to do so by taking advantage of arbitrage opportunities. 
4) The measures should be consistent with standard financial market equilibrium conditions.

If any of these conditions is not met, there is at least one way for active portfolio managers to enhance or manipulate their score by using strategies that result in seemingly better risk-return distributions but in reality achieve the higher score without genuine performance and without increasing the utility of investors.

The first condition excludes the measures that only make an incomplete ranking as well as the useless ones that, for example, merely list the returns. The second condition simply states that returns in themselves are sufficient statistics, while monetary gains and losses are not. For instance, the absolute net asset value of the fund cannot be relevant in ranking. Just because one fund has more assets than the other, the former does not necessarily perform better. The third and fourth conditions express that uninformed investors cannot profit by deviating from the benchmark, for example by trying to change the investment fund's score on the observable data, whereas the exploitation of arbitrage opportunities should be reflected in the score. The measure should not be enhanced without value or information added by, for example, using simple return smoothing, the manipulated reporting of averaged returns or completely shifting to risk-free investments after a lucky streak to reduce volatility. At the same time, the measure should detect the investment decisions that genuinely increase utility, and consequently assign higher and higher scores to these results. The authors show that these conditions are fulfilled if the measure is:

- increasing for the returns (monotonic),

- concave,

- time-separable,

- shaped as a power function.

The first condition ensures that the measure acknowledges arbitrage opportunities. The second prevents the achievement of higher scores merely by increasing leverage or adding unpriced risk. In other words, not only the returns but also the risks taken matter. The third condition prevents dynamic or temporal manipulation. The fourth ensures consistency with the financial market equilibrium theory, and the different returns should be taken from different times to replace returns from different outcomes. 
The Ingersoll measure, which meets these conditions, is the following (1):

$$
\hat{\Theta}=\frac{1}{(1-\rho) \Delta t} \ln \left(\frac{1}{T} \sum_{t=1}^{T}\left[\frac{1+r_{t}}{1+r_{f t}}\right]^{1-\rho}\right) .
$$

where $\hat{\Theta}$ estimates the risk-adjusted return premium of the investment fund. For a given $\hat{\Theta}$, the portfolio's score is the same as the annualised return of a continuously compounded risk-free asset, which is higher than the risk-free rate by the value of $\hat{\Theta}$. $r_{t}$ is the return of the fund, $r_{f t}$ is the risk-free rate and $\rho$ is the relative risk aversion ratio. If $\rho=1$, then measure (1) is not interpretable. If $\rho>1$, then measure (1) usually takes a positive value, since the ratio of $1+r_{t}$ and $1+r_{f t}$ is generally greater than 1 , and $1-\rho$ is negative in the denominator of the first fraction and the exponent, therefore the logarithm is also negative, while the product is positive. And if $\rho<1$, measure (1) is still expected to take a positive value by the former logic, but in this case $1-\rho$ has a positive value in both places, and the logarithm is also positive, just like the product.

The MPPM can also be identified with the benchmark index. For the uninformed investors, the benchmark should be a desirable, ideal investment target with a high score. If the lognormal return of the benchmark is $1+r_{b}$, then the parameter $\rho$ is the following:

$$
\frac{\ln \left[E\left(1+r_{b}\right)\right]-\ln \left(1+r_{f}\right)}{\operatorname{Var}\left[\ln \left(1+r_{b}\right)\right]}
$$

$\rho$ usually has a value between 0.2 and 10 , according to empirical evidence from the literature. Arrow (1971) argues that it is around 1, the results of Szpiro and Outreville (1988) show that it is between 1 and 5, and the average ratio is 2.89. Layard et al. (2008) also observed values of roughly 1 . It is approximately 2 according to the studies by Friend and Blume (1975) and Kydland and Prescott (1982). Gandelman and Hernandez-Murillo (2015) claim that it varies across countries, with a typical value of 1 , and even the values of outlier countries are within the $0-3$ range.

Both the Ingersoll and the Brown measure used risk aversion factors between 2 and 4. Ingersoll et al. (2007) justified this by stating that even though according to empirical data it would be theoretically possible to make the calculations with a broader range, the relative risk aversion factor of between 2 and 4 corresponds to portfolios whose leverage is between 1.75 and 0.75 . And this range covers most funds to be ranked. The selected Hungarian investment funds exhibit similar values based on the portfolio reports: out of 32 funds 23 , or 72 per cent of the funds under review, belong to this range. Brown et al. (2010) decided to use risk aversion factors 
between 2 and 4 to facilitate comparability to the results by Ingersoll et al. (2007). To ensure comparability here as well, risk aversion factors between 2 and 4 are used in the calculations below.

\section{Detecting manipulated performance and defining the doubt ratio}

According to the Brown formula, the linear approximation of MPPM (1) is:

$$
\hat{\Theta}(p)=\frac{1}{\Delta t}\left\{\bar{x}+\frac{1-\rho}{2}\left(s_{x}^{*}\right)^{2}\right\},
$$

where $\bar{x}$ is the average of the excess return and $\left(s_{x}^{*}\right)^{2}=s_{x}^{2}(T-1) / T$ is the variance of the excess return calculated from the sample.

This MPPM version allowed the simple statement of the so-called doubt ratio (DR), which deduces the development of implied risk aversion from the measure values calculated from various risk aversion ratios.

$$
D R=\frac{\hat{\Theta}(2)}{\hat{\Theta}(2)-\hat{\Theta}(3)}+2 \approx \frac{2 \bar{x}}{\left(s_{x}^{*}\right)^{2}}+1
$$

An extremely high doubt ratio suggests extreme risk aversion, which is a potential sign of performance manipulation. Brown et al. (2010) found 34 hedge funds with doubt ratios of over 150 at a 5 per cent significance level, representing 2 per cent of the total sample under review. 80 per cent of these 34 funds were flagged as suspicious by five alternative statistical approaches with respect to return manipulation, so the analysis performed with the doubt ratio is consistent with the other statistical methods indicating manipulation, and an extremely high doubt ratio is a good indicator of potential performance manipulation or return smoothing (see Table 1). 


\begin{tabular}{|c|c|c|c|c|c|c|c|}
\hline \multicolumn{8}{|c|}{$\begin{array}{l}\text { Table } 1 \\
\text { Funds with an extremely high doubt ratio }\end{array}$} \\
\hline \multirow[t]{2}{*}{ Style } & \multicolumn{3}{|c|}{ Not detected } & \multirow[b]{2}{*}{$<1 \%$} & \multicolumn{2}{|c|}{ Detected } & \multirow[t]{2}{*}{ Total } \\
\hline & $<1 \%$ & $<5 \%$ & $\%$ & & $<5 \%$ & $\%$ & \\
\hline Convertible arbitrage & 0 & 0 & $0.0 \%$ & 0 & 0 & $0.0 \%$ & 38 \\
\hline Emerging markets & 1 & 1 & $1.0 \%$ & 2 & 2 & $2.0 \%$ & 98 \\
\hline Equity market neutral & 0 & 0 & $0.0 \%$ & 3 & 3 & $4.6 \%$ & 65 \\
\hline Event-driven & 0 & 2 & $1.5 \%$ & 2 & 5 & $3.7 \%$ & 135 \\
\hline Fixed-income arbitrage & 1 & 1 & $1.8 \%$ & 0 & 2 & $3.6 \%$ & 55 \\
\hline Fund of funds & 0 & 0 & $0.0 \%$ & 9 & 11 & $2.1 \%$ & 531 \\
\hline Global macro & 0 & 0 & $0.0 \%$ & 0 & 0 & $0.0 \%$ & 53 \\
\hline Long/short equity hedge & 1 & 1 & $0.2 \%$ & 0 & 1 & $0.2 \%$ & 489 \\
\hline Managed futures & 0 & 0 & $0.0 \%$ & 0 & 0 & $0.0 \%$ & 125 \\
\hline Multi-strategy & 1 & 2 & $1.7 \%$ & 1 & 3 & $2.5 \%$ & 121 \\
\hline Total & 4 & 7 & $0.4 \%$ & 17 & 27 & $1.6 \%$ & 1710 \\
\hline
\end{tabular}

\section{Calculating MPPM and the doubt ratio on return data of Hungarian absolute return investment funds}

The MPPM and doubt ratio values calculated with the two different methods are compared here using data on absolute return funds traded in Hungary and denominated in HUF. 32 investment funds listed in Table 2 were picked for the analysis that are in the category of absolute return investment funds, denominated in HUF, public, open-end, and whose return data for the analysis period between 28 April 2010 and 27 April 2017 were available on the website of the Association of Hungarian Investment Fund and Asset Management Companies (BAMOSZ) at the time when the data were downloaded, comprising a total of 56,832 daily returns. When choosing the analysis period, it was crucial that the sample cover a period without structural breaks and contain funds traded continuously until the date of download to ensure consistent comparisons. Since the analysis seeks to compare the Ingersoll and the Brown approach and not to measure the overall market performance in the segment of absolute return investment funds, any potential survivorship bias (the bias or overestimation of measured performance arising from the fact that only those funds are examined that operated from the beginning to the end of the period under review, so the results are not adjusted downwards by the poor performance of the funds that ceased operating in the meantime, Elton et al. $1996 b)$ probably has a negligible effect on the comparison of the two methods on the sample. 


\section{Table 2}

\section{The selected absolute return funds}

\begin{tabular}{|c|c|c|}
\hline No. & Name of fund & ISIN code of fund \\
\hline 1 & Aberdeen Diversified Growth Fund of Funds Class "B" & HU0000704549 \\
\hline 2 & Aberdeen Diversified Growth Fund of Funds Class "I" & HU0000704556 \\
\hline 3 & Aegon Alfa Absolute Return Investment Fund & HU0000703970 \\
\hline 4 & AEGON MoneyMaxx Expressz & HU0000703145 \\
\hline 5 & Aegon ÓzonMaxx Total Return Investment Fund & HU0000705157 \\
\hline 6 & AEGON Smart Money Investment Fund of Funds & HU0000708169 \\
\hline 7 & Budapest Control Total Return Derivatives Fund & HU0000702741 \\
\hline 8 & Citadella Derivative Investment Fund & HU0000707948 \\
\hline 9 & Concorde Columbus Global Value Derivative Investment Fund & HU0000705702 \\
\hline 10 & Concorde PB2 Fund of Funds & HU0000704705 \\
\hline 11 & Concorde Rubicon Derivative Investment Fund & HU0000707252 \\
\hline 12 & Concorde VM Absolute Derivative Investment Fund & HU0000703749 \\
\hline 13 & Erste DPM Open-ended Alternative Fund of Funds & HU0000705314 \\
\hline 14 & Erste Multistrategy Absolute Return Fund of Funds & HU0000705322 \\
\hline 15 & Generali IPO Absolute Return Fund & HU0000706791 \\
\hline 16 & Generali Spirit Absolute Derivative Fund & HU0000706833 \\
\hline 17 & Generali Titanium Total Return Fund & HU0000706817 \\
\hline 18 & OTP Absolute Return Open-ended Derivative Fund & HU0000704457 \\
\hline 19 & OTP EMDA Derivative Fund & HU0000706361 \\
\hline 20 & OTP G10 Euro Derivative Fund & HU0000706221 \\
\hline 21 & OTP Supra Derivative Investment Fund & HU0000706379 \\
\hline 22 & OTP New Europe Open-ended Securities Fund & HU0000705827 \\
\hline 23 & Platina Alfa Derivative Investment Fund & HU0000704648 \\
\hline 24 & Platina Beta Derivative Investment Fund & HU0000704655 \\
\hline 25 & Platina Delta Derivative Investment Fund & HU0000704671 \\
\hline 26 & Platina Gamma Derivative Investment Fund & HU0000704663 \\
\hline 27 & Platina Pi Derivative Investment Fund & HU0000704689 \\
\hline 28 & Raiffeisen Hozam Premium Derivative Fund & HU0000703699 \\
\hline 29 & Raiffeisen Index Premium Derivative Fund & HU0000703707 \\
\hline 30 & Raiffeisen Private Pannonia Fund of Funds & HU0000705231 \\
\hline 31 & Sovereign PB Derivatives Fund & HU0000707732 \\
\hline 32 & Takarek Total Return Investment Fund & HU0000707997 \\
\hline
\end{tabular}

Note: On 11 September 2017 Concorde Asset Management was renamed to HOLD Asset Management. 


\subsection{Treatment of the risk-free rate}

The risk-free rate used was the 12-month benchmark rate of the Government Debt Management Agency, because the return on these short-term government securities is risk-free and it also accurately reflects the major changes of the risk-free rate in the period under review. The MPPM was calculated taking into account the monthly changes in the 12-month benchmark rate. To calculate the daily continuously compounded risk-free rate for the given period, one has to take the value of the relevant monthly risk-free rate and transform with the logarithmic function the nominal annual return shown in the Government Debt Management Agency's database with effective return calculation, then prorate it from the annualised return to daily return, for 250 trading days, using the following formula:

$$
r_{f t(\text { continuous })}=\frac{\ln \left(\frac{100+R_{f t}}{100}\right)}{250} .
$$

\subsection{Treatment of the fund returns}

The daily log returns can be determined by downloading the daily unit price data from the BAMOSZ website and using the following formula:

$$
r_{t}=\ln \left(\frac{P_{t}}{P_{t-1}}\right) \text {. }
$$

\subsection{Determining MPPM values with the Ingersoll formula}

The Ingersoll MPPM values need to be determined for $\rho=2, \rho=3$ and $\rho=4$. In all three cases, first the return premium from the given period over the risk-free rate should be raised to the power of $1-\rho$ to adjust the return ratio by the risk:

$$
\text { Risk adjusted return premium }=\left(\frac{1+r_{t}}{1+r_{f t}}\right)^{1-\rho},
$$

then the log of the average risk-adjusted return premium calculated for the whole period is divided by $1-\rho$ :

$$
\frac{1}{(1-\rho)} \ln \left(\frac{1}{T} \sum_{t=1}^{T} \text { Risk adjusted return premium } t\right) \text {. }
$$

Finally, the value of $\hat{\Theta}$ calculated for the daily returns is annualised by multiplying it for 250 trading days.

$$
\hat{\Theta}_{\text {Ingersoll }}=\frac{1}{\Delta t} \hat{\Theta}_{\text {daily }} \text {. }
$$


$\hat{\Theta}$ estimates the risk-adjusted return premium of the investment fund. In other words, a given $\hat{\Theta}$ is the portfolio's score that equals the continuously compounded and annualised return of a risk-free asset, exceeding the risk-free rate by $\hat{\Theta}$.

\subsection{Determining MPPM values with the Brown formula}

In the Brown approach, the MPPM can be stated as the difference between the average excess return and the variance of the excess return calculated from the sample, where the coefficient of the variance is $(1-\rho) / 2$.

Thus, to calculate the Brown MPPM, one first needs to calculate the average excess return by taking the log of the ratio of the daily return of the investment fund and the risk-free rate for each day:

$$
\text { Return premium }=\ln \left(\frac{1+r_{t}}{1+r_{f t}}\right),
$$

then their average is calculated for the whole period:

$$
\bar{x}=\frac{1}{T} \sum_{t=1}^{T} \text { Return premium } ._{t}
$$

In the Brown approach, the other building block is the calculation of the variance of the excess return calculated from the sample.

Finally, the difference between the two values is calculated for the three $\rho$ 's $(2,3$ and 4$)$, where the coefficient of variation is $(1-\rho) / 2$. The daily $\hat{\Theta}$ value derived in this manner is prorated for annualised return by multiplying it by 250 trading days.

$$
\hat{\Theta}_{\text {Brown }}=\frac{1}{\Delta t} \hat{\Theta}_{\text {daily }}
$$

\subsection{Comparison of the Ingersoll and Brown MPPM values and rankings}

This is one of the first studies to compare the MPPM values calculated with the Ingersoll and the Brown formula. Very similar results were derived for the MPPM with respect to both the value of the measure and the ranking (Table 3, where, for example, "MPPM(3)" in the Ingersoll section means the MPPM value calculated with the Ingersoll formula and a risk aversion factor of 3, while "MPPM(3) rank" means the ranking of the fund calculated with the same formula). In quantifiable terms, this means that correlation is 1 for the MPPM values with a risk aversion 
factor of 2, and around 0.9999 even with a parameter of 3 or 4 . And the rank correlation takes a value of 1 even with a risk aversion factor of 2 or 4 , exhibiting full consistency, while it is 0.9996 with a factor of 3 , exhibiting almost full consistency, which means that out of the 32 funds under review, 30 received the same ranking calculated with the two approaches, and only two funds switch ranks. Out of the 96 cases of the MPPM ranking of the 32 funds calculated with 3 different risk aversion factors, there were only 2 differences: therefore, consistency is 97.92 per cent for the two methods.

The percentage differences of the MPPM values derived from the two calculation methods are usually below 1 per cent (See Table 3 under "Ingersoll-Brown $\Delta \%$ "). In the case of the OTP EMDA fund, there is a difference of 79.9 per cent with a risk aversion of 4 , which is the greatest percentage difference, but this does not alter the ranking. This is partly because the MPPM values are very close to 0 (Ingersoll MPPM -0.0003, Brown MPPM -0.0005), thus the relatively small change in absolute value (the value of +0.0002 seen in the "Ingersoll-Brown $\Delta$ " section of Table 3 under MPPM(4)) means a large percentage change between the two calculation methods. On the other hand, compared to the relatively small change in absolute value, the MPPM value of the next-ranked investment fund is sufficiently far away.

When changing from the Ingersoll to the Brown formula and using a risk aversion factor of 3, the OTP Supra fund sticks out and switches places with the Concorde Columbus fund. While the Concorde Columbus values calculated with the two methods are identical to six decimal places for all risk aversion factors, in the case of the OTP Supra, the MPPM value increases by 2.66 per cent with a risk aversion factor of 3 when the Brown approach is used, which is the second greatest difference in absolute terms (0.0013). The change in the OTP Supra fund's MPPM that also influences ranking is attributable to the fact that while this fund generates the second largest returns, and the standard deviation of its returns is the fourth greatest, based on the results, the Brown linear approximation of the MPPM penalises risk less than the Ingersoll approach. The switched ranking of the two funds is also due to the fact that with a risk aversion factor of 3 there is a relatively large difference between the two approaches in absolute terms, and compared to that the difference between the MPPM values of the two funds is relatively small. 


\begin{tabular}{|c|c|c|c|c|}
\hline \multicolumn{5}{|c|}{$\begin{array}{l}\text { Table } 3 \\
\text { Comparison of the Ingersoll and Brown MPPM values and rankings }\end{array}$} \\
\hline & $\begin{array}{l}\text { Concorde } \\
\text { Columbus }\end{array}$ & $\begin{array}{l}\text { Sovereign PB } \\
\text { Derivatives }\end{array}$ & $\begin{array}{l}\text { OTP } \\
\text { EMDA }\end{array}$ & $\begin{array}{l}\text { OTP } \\
\text { Supra }\end{array}$ \\
\hline \multicolumn{5}{|l|}{ Ingersoll } \\
\hline MPPM(2) & 0.0500 & -0.0523 & 0.0435 & 0.0612 \\
\hline MPPM(3) & 0.0486 & -0.0544 & 0.0216 & 0.0475 \\
\hline MPPM(4) & 0.0472 & -0.0566 & -0.0003 & 0.0330 \\
\hline MPPM(2) rank & 6 & 32 & 8 & 2 \\
\hline MPPM(3) rank & 5 & 31 & 10 & 6 \\
\hline MPPM(4) rank & 5 & 31 & 16 & 7 \\
\hline \multicolumn{5}{|l|}{ Brown } \\
\hline MPPM(2) & 0.0500 & -0.0523 & 0.0435 & 0.0615 \\
\hline MPPM(3) & 0.0486 & -0.0542 & 0.0215 & 0.0488 \\
\hline MPPM(4) & 0.0472 & -0.0561 & -0.0005 & 0.0361 \\
\hline MPPM(2) rank & 6 & 32 & 8 & 2 \\
\hline MPPM(3) rank & 6 & 31 & 10 & 5 \\
\hline MPPM(4) rank & 5 & 31 & 16 & 7 \\
\hline \multicolumn{5}{|l|}{ Ingersoll-Brown $\Delta$} \\
\hline MPPM(2) & $8.10673 \mathrm{E}-07$ & $-5.02266 \mathrm{E}-05$ & $3.8088 \mathrm{E}-05$ & -0.000291847 \\
\hline MPPM(3) & $1.65408 \mathrm{E}-06$ & -0.0002099 & 0.000122 & -0.001266 \\
\hline MPPM(4) & $2.51586 \mathrm{E}-06$ & -0.0004900 & 0.000243 & -0.003065 \\
\hline MPPM(2) rank & 0 & 0 & 0 & 0 \\
\hline MPPM(3) rank & -1 & 0 & 0 & 1 \\
\hline MPPM(4) rank & 0 & 0 & 0 & 0 \\
\hline \multicolumn{5}{|c|}{ Ingersoll-Brown $\Delta \%$} \\
\hline MPPM(2) & 0.0016 & 0.0960 & 0.0875 & -0.4768 \\
\hline MPPM(3) & 0.0034 & 0.3860 & 0.5642 & -2.6627 \\
\hline MPPM(4) & 0.0053 & 0.8663 & -79.92 & -9.2836 \\
\hline
\end{tabular}

Note: In the table, yellow denotes the cases where the rankings were switched when calculated with the Ingersoll and the Brown approach, while orange denotes the cases where the MPPM values differed substantially between the two methods (either in absolute value or relatively).

\subsection{Comparison of the doubt ratio values calculated from the Ingersoll and the Brown MPPM and the Brown approximation}

Until now, the doubt ratio has never been calculated in practice with the Ingersoll and the Brown formula to compare the results. The doubt ratio can be determined based on Brown et al. (2010) (3) by comparing the MPPM values calculated with 
different risk aversion ratios and estimating the value of the implied risk aversion ratio. Based on the Ingersoll MPPM ${ }^{4}$ values, the formula is as follows:

$$
D R=\frac{\hat{\Theta}_{\text {Ingersoll }}(2)}{\hat{\Theta}_{\text {Ingersoll }}(2)-\hat{\Theta}_{\text {Ingersoll }}(3)}+2
$$

Based on the Brown MPPM ${ }^{5}$ values, the formula is modified as follows:

$$
D R=\frac{\hat{\Theta}_{\text {Brown }}(2)}{\hat{\Theta}_{\text {Brown }}(2)-\hat{\Theta}_{\text {Brown }}(3)}+2
$$

According to the Brown approximation, the doubt ratio can also be calculated as the ratio of the average excess return and the variance of the excess return calculated from the sample:

$$
D R \approx \frac{2 \bar{x}}{\left(s_{x}^{*}\right)^{2}}+1
$$

The doubt ratio value is practically almost identical when calculated using the formula based on the Brown MPPM or the Brown approximation (to 13 decimal places); thus, the calculated ranking is also identical, and rank correlation and correlation take a value of 1 , exhibiting full consistency. When calculating from the Ingersoll or the Brown MPPM (or using the Brown approximation), very similar results are obtained: the correlation and the rank correlation are 0.999 . The doubt ratio ranking is identical with all three calculation methods in 29 cases out of the 32 investment funds under review, representing 90.6 per cent of the funds.

Only two funds exhibited major differences in the doubt ratio values calculated with the Ingersoll and the Brown MPPM (and the Brown approximation) (Table 4 "DR(Ingersoll)-DR(Brown) $\Delta$ " and "DR(Ingersoll)-DR(Brown approximation) $\Delta$ "): OTP Supra and Sovereign PB Derivatives. The different values cause a change in ranking in only the latter case (Table 4 „DR(Ingersoll)-DR(Brown) ranking $\Delta^{\prime \prime}$ ). The 5.65 per cent change in the case of the OTP Supra fund is relatively small in absolute terms, and the subsequent doubt ratio value is sufficiently far away. However, the Sovereign PB Derivatives Fund is ranked two places lower in the Brown ranking than in the Ingersoll ranking, whereas the Raiffeisen Hozamprémium és Raiffeisen Indexprémium values that precede it are hardly modified, and there was no change in their relative ranking either. The change in ranking is ultimately caused by the major drop in value ( -8.97 per cent) in the Sovereign PB Derivatives Fund, and the fact that the subsequent funds' doubt ratio values are close enough to

\footnotetext{
${ }^{4}$ See formula (1).

${ }^{5}$ See formula (2).
} 
enable a change in rankings. This fund exhibited the third largest MPPM change in absolute value and the fourth largest percentage change with a risk aversion factor of 3 when calculated with the Brown approach compared to the Ingersoll version (0.386 per cent), and the results show that the MPPM difference was magnified when transferred to the doubt ratio values (8.97 per cent).

\subsection{Comparison of the Ingersoll and the Brown method based on practical applicability and the complexity of their implementation, proposal for the preferred method}

The calculations showed the applicability and the difficulty of implementation as well as practical aspects of the differences between the methods in the case of 32 Hungarian absolute return investment funds.

With respect to MPPM calculation, there is no major difference between the two approaches as regards difficulty or the necessary calculation steps. While the Ingersoll formula takes the average of the risk-adjusted return premia in the period, and then adjusts it with a logarithm and the risk aversion factor, the Brown approach calculates using the simple difference of the average excess returns in the period and the variance, where the risk aversion factor is included as the coefficient of variation. So the Brown approach uses an additional step when calculating the variance of excess returns, and this facilitates the better understanding of the logic behind the MPPM structure by quantifying risk. Since the Brown MPPM is a linear approximation of the more accurate Ingersoll MPPM, and according to the calculations there are differences between the two methods that influence ranking, the Ingersoll approach should be used to calculate MPPM. The calculation of the Brown MPPM or the steps necessary for that are recommended if the analysis also seeks to find out the average and standard deviation of excess return to ensure the better understanding of the correlations.

The calculation of the doubt ratio includes the same steps using both the Ingersoll and the Brown MPPM values (or the Brown approach to the doubt ratio); therefore, they require exactly the same effort. Taking into account the observed inaccuracy of the Brown MPPM formula arising from the linear approach, the doubt ratio can be more accurately calculated from the Ingersoll MPPM, and therefore the use of the latter is recommended. 


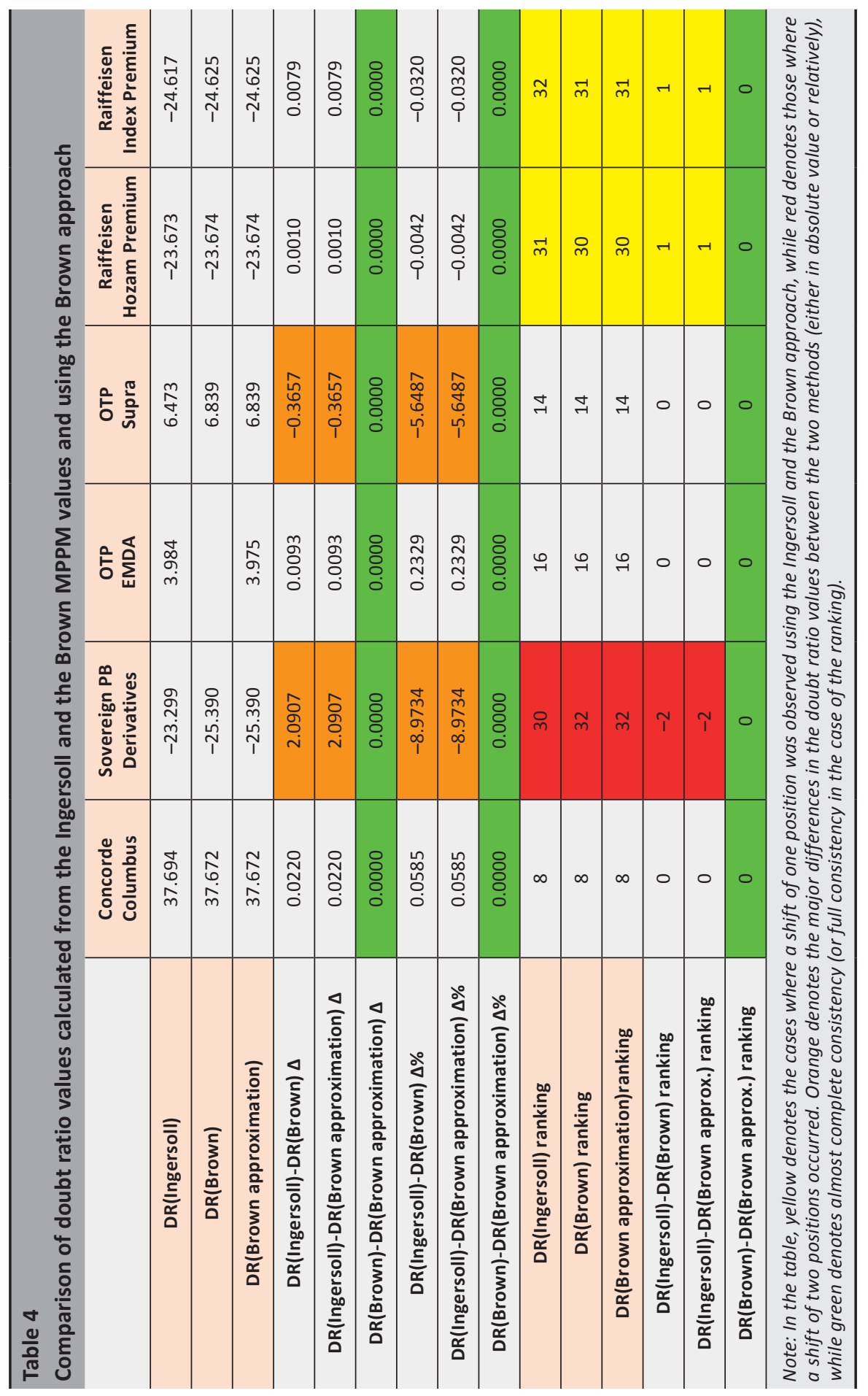




\section{Summary, conclusions}

The development of performance measures has managed to remedy the problems of earlier solutions, but in the case of the measures popular in the literature and used most widely today, the issue of performance manipulation still needs to be tackled. This article outlined the Ingersoll manipulation-proof performance measure, which solves this general problem when assessing investment funds and hedge funds. The Brown MPPM version was also described, which is the linear approximation of the Ingersoll measure. Furthermore, the doubt ratio developed by Brown et al. (2010) was presented, which can be used as a manipulation-detecting measure because it measures implied risk aversion. By using data from Hungarian absolute return funds for our own calculations, it was shown how the change in MPPM and implied risk aversion can be calculated in practice using the measures of the two groups of authors.

This was among the first comparisons of the MPPMs calculated with the two different methods, and the first in the case of the doubt ratio. It was shown that the results of the Ingersoll and the Brown MPPM and doubt ratio almost completely overlap, and the reasons behind the small number of differences observed were examined.

In the case of the MPPM, the ranking is the same with both methods for all 32 funds, using a risk aversion factor of 2 or 4 . Only the risk aversion factor of 3 produced differences, and even then 30 out of the 32 funds under review received the same ranking, with only two switching places when calculated with the different approaches. This is partly because with a risk aversion factor of 3 , the difference between the MPPM values of the two funds is relatively small, whichever method is used. On the other hand, one of the two funds concerned has the second largest returns and the fourth largest standard deviation of returns, while the other has average values in terms of both, and the results attest that the Brown linear approximation of the MPPM penalises risk less than the Ingersoll approach.

When calculating the doubt ratio from the Ingersoll and the Brown MPPM (and using the Brown approximation), very similar results are derived, the correlation and the rank correlation are 0.999 . The ranking is identical with all three calculation methods in 29 cases out of the 32 investment funds under review, representing 90.6 per cent of the funds. The difference is attributable to the fact that a huge drop in value is observed in the case of one fund between the Ingersoll and the Brown approach, and the subsequent funds' doubt ratio values are also relatively close, while their values are not significantly modified, and they retain their relative ranking. This fund exhibited the third largest MPPM change in absolute value and the fourth largest percentage change with a risk aversion factor of 3 when calculated with the Brown approach compared to the Ingersoll version ( -0.386 per cent), and 
the results show that the MPPM difference was magnified when transferred to the doubt ratio values (8.97 per cent).

The results of the calculation led to the following conclusions:

1. The Brown linear approximation of the MPPM penalises risk less than the Ingersoll approach.

2. The larger changes in the MPPM values observed between the Ingersoll and the Brown approach are usually magnified when transferred to the doubt ratio calculated from them.

3. A change in ranking between the two methods is seen for both the MPPM and the doubt ratio if the observed change is large enough and the values of the funds ranked near the fund concerned are close enough to its values, so that this change in value affects ranking.

4. Since there is no significant difference between the Ingersoll and the Brown MPPM calculation as regards difficulty or the number of steps required, and since the Brown approach, the inaccuracy of which sometimes alters the ranking, is merely a linear approximation of the Ingersoll MPPM, the MPPM calculation is recommended to be performed using the more accurate Ingersoll approach. However, the Brown method may be useful for analysis purposes when calculating the average and standard deviation of excess return.

5. This first comparison showed that the doubt ratio can be more accurately calculated from the Ingersoll MPPM, therefore the use of this approach is recommended.

\section{References}

Arrow, K.J. (1971): Essays in theory of risk-bearing. North-Holland Pub. Co., Amsterdam.

Abdulali, A. (2006): The Bias Ratio: Measuring the Shape of Fraud. Protégé Partners Quarterly Letter, 3rd Quarter.

Amihud, Y. - Hameed, A. - Kang, W. - Zhang, H. (2015): The illiquidity premium: International evidence. Journal of Financial Economics, 117(2): 350-368. https://doi.org/10.1016/j. jfineco.2015.04.005

Blake, C.R. - Elton, E.J. - Gruber, M.J. (1993): The performance of bond mutual funds. Journal of Business, 66(3): 371-403. https://doi.org/10.1086/296609

Balog, D. - Bátyi, T. - Csóka, P. - Pintér, M. (2017): Properties and comparison of risk capital allocation methods. European Journal of Operational Research, 259(2): 614-625. https:// doi.org/10.1016/j.ejor.2016.10.052 
Bollen, N.P.B. - Pool, V.K. (2009): Do Hedge Fund Managers Misreport Returns? Evidence from the Pooled Distribution. Journal of Finance, 64(5): 2257-2288. https://doi.org/10.1111/ j.1540-6261.2009.01500.x

Brown, S. - Kang, M. - In, F. - Lee, G. (2010): Resisting the Manipulation of Performance Metrics: An Empirical Analysis of the Manipulation-Proof Performance Measure. New York University Working Paper. https://doi.org/10.2139/ssrn.1536323

Bóta, G. (2014): A magyarországi befektetési alapok teljesítményét meghatározó tényezők vizsgálata (Examining the major factors determining the performance of Hungarian investment funds). Hitelintézeti Szemle, 13(2): 147-163.

Bóta, G. - Ormos, M. (2016): Is There a Local Advantage for Mutual Funds That Invest in Eastern Europe? Eastern European Economics, 54(1): 23-48. https://doi.org/10.1080/0 0128775.2015 .1120161

Carhart, M.M. (1997): On persistence in mutual fund performance. The Journal of Finance, 52(1): 57-82. https://doi.org/10.1111/j.1540-6261.1997.tb03808.x

Csóka, P. - Pintér, M. (2016): On the impossibility of fair risk allocation. The B.E. Journal of Theoretical Economics, 16(1): 143-158. https://doi.org/10.1515/bejte-2014-0051

Elton, E.J. - Gruber, M.J. - Blake, C.R. (1996a): The persistence of risk-adjusted mutual fund performance. Journal of Business, 69(2): 133-157. https://doi.org/10.1086/209685

Elton, E.J. - Gruber, M.J. - Blake, C.R. (1996b): Survivorship Bias and Mutual Fund Performance. Review of Financial Studies. 9(4): 1097-1120. https://doi.org/10.1093/ rfs/9.4.1097

Erdős, P. - Ormos, M. (2009): Return calculation methodology: Evidence from the Hungarian mutual fund industry. Acta Oeconomica, 59(4): 391-409. https://doi.org/10.1556/ AOecon.59.2009.4.2

Friend, I. - Blume, M.E. (1975): The demand for risky assets. American Economic Review, 65(2): 900-922.

Gandelman, N. - Hernandez-Murillo, R. (2015): Risk Aversion at the Country Level. Review, 97(1): 53-66. https://doi.org/10.20955/r.2015.53-66

Gemmill, G. - Hwang, S. - Salmon, M. (2006): Performance measurement with loss aversion. Journal of Asset Management 7(3-4): 190-207. https://doi.org/10.1057/palgrave. jam. 2240213

Ingersoll, J. - Spiegel, M. - Goetzmann, W. - Welch, I. (2007): Portfolio Performance Manipulation and Manipulation-proof Performance Measures. The Review of Financial Studies 20(5): 1503-1546. https://doi.org/10.1093/rfs/hhm025 
Jensen, M. (1969): Risk, the pricing of capital assets, and the evaluation of investment portfolios. Journal of Business, 42(2): 167-247. https://doi.org/10.1086/295182

Kydland, F.E. - Prescott, E.C. (1982): Time to build and aggregate fluctuations. Econometrica, 50(6): 1345-1370. https://doi.org/10.2307/1913386

Layard, R. - Mayraz. G. - Nickell, S. (2008): The Marginal Utility of Income. Journal of Public Economics, 92(8-9): 1846-1857. https://doi.org/10.1016/j.jpubeco.2008.01.007

Mas-Colell, A. - Whinston, M.D. - Green, J.R. (1995): Microeconomic Theory. Oxford University Press, New York.

Pojarliev, M. - Levich, R.M. (2013): Evaluating Absolute Return Managers. Financial Markets and Portfolio Management, 28(1): 95-103. https://doi.org/10.2139/ssrn.2333210

Sharpe, W.A. (1966): Mutual Fund Performance. Journal of Business, 39(1/2): 119-138. https://doi.org/10.1086/294846

Szpiro, G.G. - Outreville, J-F. (1988): Relative Risk Aversion Around the World: Further Results. Journal of Banking and Finance, 6(S1): 127-128. https://doi.org/10.1016/03784266(88)90063-5

Treynor, J. - Black, F. (1973): How to Use Security Analysis to Improve Portfolio Selection. Journal of Business, 46(1): 66-86. https://doi.org/10.1086/295508

Zawadowski, Á. (2017): Kezelési költségük határozza-e meg a Magyarországon forgalmazott részvénypiaci befektetési alapok teljesitményét? (Do fees determine the performance of stock mutual funds sold in Hungary?) Közgazdasági Szemle (Economic Review), 64(11): 1186-1201. https://doi.org/10.18414/KSZ.2017.11.1186

Qian, M. - Yu, B. (2015): Do mutual fund managers manipulate? Applied Economics Letters, 22(12): 967-971. https://doi.org/10.1080/13504851.2014.993124 